\title{
Conceptualization of Socioscientific Issues in Educational Practice from a Review of Research in Science Education
}

\author{
S. Alcaraz-Dominguez and M. Barajas
}

\begin{abstract}
The pedagogical use of Socioscientific Issues (SSI) in formal education has increased in the last decade, specifically as a way to improve STEM teaching processes and results. However, several theoretical interpretations coexist about SSI in formal education, thus posing a challenge to developing knowledge from practice. An examination of recent papers was conducted to elicit the conceptualizations of SSI in science education research according to three theoretical dimensions of the curriculum: purpose, contents, and teaching and learning strategies. Results show that as for purpose, SSI is currently conceptualized as citizenship education, and scientific literacy or competence. As for contents, SSI is related both to knowledge of science and knowledge about science, as well as some skills such as argumentation. Finally, SSI is associated to pedagogical strategies, mainly Inquiry-Based Learning; and to pedagogical techniques such as dilemmas and group discussions. This conceptualization sets up foundations for the design and evaluation of innovative SSI educational practices. It shall also help to promote new lines of research that establish connections among practical applications of SSI in different subjects, cultural contexts, and educational systems.
\end{abstract}

Index Terms-Educational innovation, formal education, STEM, literature review, science education, socioscientific issues, SSI.

\section{INTRODUCTION}

In the last years, Science, Technology, Engineering and Mathematics (STEM) have become a priority in public policy, especially in socio-economic and cultural settings where science and technology have high value as a way to progress and contribute to economic growth [1]. Consistently, the educational systems worldwide are demanding a higher representation of STEM throughout all levels.

In order to improve STEM teaching and learning processes and results in formal education, public funding has been invested in promoting several innovations. These are based on digital learning resources and tools, such as remote laboratories, for example, the Go-Lab project [2], videogames or augmented reality [3], [4]. Other projects innovate in the STEM teaching and learning processes, by introducing Project-Based Learning or Inquiry-Based Learning, for example the Pathway project [5].

One of these innovations consists of introducing Socioscientific Issues (SSI) as a strategy to engage students

Manuscript received November 12, 2020; revised March 1, 2021. This work was supported in part by the European Union Seventh Framework Programme under Grant agreement number 612269.

The authors are with Universitat de Barcelona, College of Education, Department of Didactics and Educational Organization, Spain (e-mail: silvia.alcaraz@ub.edu,mbarajas@ub.edu). in learning STEM subjects, as well as to convey the growing importance that science and technology have in society. SSI have been defined as "complex and contentious social issues with substantial connections to science ideas and principles" [6]. Examples of SSI are: global warming, genetically modified organisms, sustainability, etc.

The key elements inspiring the pedagogical application of SSI are that they 1) Constitute practical applications of scientific knowledge to real life problems, 2) They convey the socially constructed nature of developing scientific knowledge, especially its moral dimension, 3) They are present in public discussion, many times through the Media [7].

As a new educational trend, the pedagogical application of SSI has gathered an interest in educational research, practice, and teacher education [8]-[10]. In terms or practice, the pedagogical use of SSI in formal education has increased in the last years and in particular in non-tertiary education. Non-tertiary education includes compulsory education and upper secondary education.

More specifically, as a heir of the Science, Technology and Society (STS) movement, knowledge about the pedagogical application of SSI in this context is developing, especially in science education research [6]. However, at a conceptual level, the pedagogical application of SSI is open to interpretation.

At a first look to the literature, there are signs that a discussion remains open about the operationalization of the pedagogical application of SSI. This lack of agreement is common of any new educational practice. In other words, SSI are not originally from education, but a real life phenomenon that is applied in an educational context. This can be interpreted as the need to elicit the existing conceptualizations of SSI in formal education.

Publications are available providing a conceptualization of SSI in formal education. For example, as a result of a Delphi Study, Irez et al. [11] propose an "SSI teaching and learning framework," which includes the following categories: Learning outcomes, Domains or cross-cutting themes, Pedagogical strategies, Features of the learning environment, Nature of the instructional materials and sources, and assessment. By using the concept of "SSI as curriculum practice," Zeidler's review of research and practice of SSI in formal education [12] is organized in four themes or ways to understand SSI in formal education: 1) the pedagogical application of classroom practice, 2) epistemological beliefs, 3) contexts for the Nature of Science, and 4) development of morality. In this sense, it can be understood as a position paper that provides one possible way to organise SSI-mediated educational practices in formal education. 
The present paper builds specifically in this line of research, to emphasize the conceptualizations that the authors of research on science education make of the pedagogical use of SSI. In particular this paper aims to eliciting these conceptualizations according to what is known as curriculum components. Curriculum components are one way to organize educational systems, and they determine how formal education is delivered in a specific region or state, by providing a common structure as expressed in regulations such as acts or legislation. These are the following: a) Purpose (objectives of formal education); b) Contents (body of knowledge, skills and attitudes that students must master as part of formal education); c) Teaching and learning methodologies (pedagogical techniques that are designed for learners to interact with the content and reach the learning objectives); d) Assessment criteria (which determine student performance standards)

Similar approaches have been used to conceptualize other innovations in educational practice, for example Inquiry-Based Learning. According to Lederman, Antink, and Bartos [13], its application to educational practice can be interpreted as a) as a set of skills to be learned ("doing science like scientists do"), b) as cognitive outcomes ("what students can do and know about inquiry") and c) as a teaching approach to transmit science knowledge to students or help them build the knowledge themselves.

\section{METHOD}

\section{A. Research Design}

Based on the problem identified, the present paper set out to answer the following research question: 1) How do the conceptualizations of SSI relate to the STEM curriculum in non-tertiary education? To answer this question, research on SSI in science education has been reviewed through a desk study of recent published papers.

Desk studies constitute one type of secondary research to the extent that they involve analyzing existing data, as opposed to collecting primary data [14]. The present study, however, differs from other techniques based on collecting information from secondary sources, such as literature review. The goal of this study is not to collect the research on the topic in a comprehensive manner, but to analyze and synthesize the conceptualizations about it that are represented in published work. For this reason the specific methodology of review of research is used, seeking to enlighten SSI in formal education through new ways of understanding.

In order to ensure validity and reliability, some principles were applied, and the recommendations by EPPI-Centre [15] for systematic reviews of research evidence in particular. Thus, criteria for specifying which studies would be included in the review were determined. In this study the criteria were: 1) Topic: literature must relate directly to the research question; 2) Type of publication: the information sources should be of academic nature, where academic nature means that they aim to contributing to knowledge development in this field; this includes journal articles, conference proceedings, books and book chapters; 3) Recency: all the sources should be from the last 15 years; 4) Geographical spread and cultural context: studies worldwide; 5) Reliability: findings upon which literature is based are valid and reliable.

\section{B. Research Procedure}

The following objectives guided the research reported in this paper: 1) To select academic publications regarding the pedagogical application of SSI in the specific case of formal STEM education; 2) Select the publications in which the authors define, in an implicit or explicit way, the concept of SSI in formal education; 3) Organize the conceptualizations of SSI from the perspective of the four dimensions of the curriculum in formal education, namely: purpose, contents, teaching and learning methodologies, and assessment.

International databases such as Web of Science and Scopus were used to access the literature. A total of twenty-four (24) papers have been reviewed. Additionally, six (6) publications of different kinds have been part of this review, including book chapters, publications in conference proceedings, books, and conference presentations.

This study targeted publications aiming to use SSI in formal non-tertiary education. Studies in science teacher education (normally preservice) were also included as long as SSI are used as way to improve the processes or results of STEM-related contents. Conversely, the review excludes papers that use other interpretations of SSI that are not in its innovative nature. For example, studies about how classroom experimentation with SSI can foster teacher professional development, for example increasing their pedagogical knowledge.

\section{RESULTS}

As a result of the review, the conceptualizations of SSI in STEM formal education were elicited. From a general perspective, the references made to curriculum component d) Assessment were not sufficient to consider them as a category in the analysis. Therefore, the conceptualizations have been synthesized and organized from the point of view of the three first dimensions of the curriculum presented above.

TABLE I: OVERVIEW OF CONCEPTUALIZATIONS IDENTIFIED

\begin{tabular}{lll}
\hline \hline Curriculum dimension & Indicator & Category \\
\hline $\begin{array}{l}\text { Purpose of STEM } \\
\text { education }\end{array}$ & $\begin{array}{l}\text { Formal education } \\
\text { in general } \\
\text { STEM or science } \\
\text { education }\end{array}$ & $\begin{array}{l}\text { Citizenship } \\
\text { education } \\
\text { Scientific } \\
\text { literacy / } \\
\text { competence }\end{array}$ \\
\hline $\begin{array}{l}\text { Contents of STEM } \\
\text { education }\end{array}$ & Knowledge & $\begin{array}{l}\text { Knowledge of } \\
\text { science } \\
\text { Knowledge } \\
\text { about science } \\
\text { Argumentation }\end{array}$ \\
\hline $\begin{array}{l}\text { Teaching and learning } \\
\text { methodologies of }\end{array}$ & Pedagogical & $\begin{array}{l}\text { Inquiry-Based } \\
\text { Learning }\end{array}$ \\
strategies & Engagement & Dilemmas \\
& techniques & Discussions \\
\hline \hline
\end{tabular}

The research reviewed may include references to SSI in more than one of these dimensions. In this case, the paper is 
referenced in both dimensions. The views are listed in Table 1 and summarized in the following sub-headings.

\section{A. Dimension "Purpose of Formal STEM Education"}

The purposes of formal education can be defined as its objectives, i.e. what a specific educational level or stage aims to achieving, as expressed in terms of student learning outcomes. According to the purpose of STEM education, SSI has been conceptualized in different ways in the papers reviewed. In particular, two main levels can be identified.

The first level establishes relations between the concept of SSI and the learning objectives associated to formal education as a whole. The most common approach is to relate SSI to the fact that formal education is a way to prepare students to actively participate in decision-making processes in society, and getting involved in STEM-related common problems (e.g. climate change, genetically modified foods, etc.). This view can be related to the citizenship education view [16].

Some of the conceptualizations of SSI found relate to the notion of Responsible Research and Innovation (RRI), for example Hadjichambis et al. [17]. RRI is a vision about the process of developing science and innovation from a societal point of view. RRI further develops the need to communicate and transfer results of research and innovation to citizens, to an approach where science and research activities take into account the values, priorities and needs of those citizens [18].

The second level refers to the goals of formal science education in particular. In some publications, SSI is presented in the context of a discussion about the definition of scientific literacy or scientific competence. Romine et al., for example, further develop the concept of scientific literacy or competence and they introduce new constructs, such as Socioscientific Reasoning (SSR), a notion that considers complexity, examining issues from different perspectives, ongoing inquiry, and skepticism [19].

\section{B. Dimension "Contents of formal STEM education"}

From this standpoint, the conceptualization of SSI relates to the contents of STEM formal education. Contents allow teachers and students to reach the objectives or purposes of formal STEM education.

Curricular contents can be stated as knowledge, skills and attitudes. The results of the present review revealed associations mainly with knowledge and some skills.

According to knowledge, the conceptualizations of SSI in formal education are organized according to two main types of scientific knowledge, which are common in research on science education: 1) knowledge of science and 2) knowledge about science. Knowledge of science includes the facts of products of the scientific activity (the laws and theories that constitute the knowledge body of science and technology), whereas knowledge about science describes the processes and resources that are involved in its development [20].

Regarding knowledge of science, some authors associate SSI with specific curricular content, e.g life sciences [21], energy systems [22], or global climate change [23]. Other authors associate SSI to scientific knowledge that is either unclear, in process of development, or unstable. This is often referred to as "science in the making" [24], and has been addressed by other publications that report on the application of SSI-mediated teaching and learning activities such as Ekborg et al. [25]. Examples of these include: nanotechnologies, stem cell research, bioengineering, etc.

Regarding knowledge about science, SSI has been presented "a means to discuss and learn about the connection between science and society" [26]. The main construct identified in the review is Nature of Science (NoS). NoS can be described as a meta-knowledge about science, i.e. how scientific activity is performed [27]. Zeidler et al. [28] refer to this as "epistemology of scientific knowledge as well as the processes/methods used to develop such knowledge" (p.358).

In addition to scientific knowledge, other more skill oriented curricular contents are related to SSI. The most emphasized is argumentation [29]-[33], and to a less extent, critical thinking and argumentation [34], categorized as Higher Order Thinking Skills (HOTS).

These contents may be part of the curriculum, but they might be overlooked in STEM teaching practice. In reference to the type of curricular content that is associated to SSI, Lundström, Sjöström, \& Hasslöf [26] refer to Simonneaux's conceptualization about SSI as a continuum: "Cold-type SSI education is quite traditional science teaching with some socio-contextualisation. It is characterised by monodisciplinarity and focus on content learning. Hot-type SSI, on the other hand, also emphasises transdisciplinarity and political citizenship" (p. 21).

\section{Dimension "Teaching and Learning Methodologies of Formal STEM Education"}

This way to conceptualize SSI relates to pedagogical strategies in formal STEM education. Pedagogical strategies allow students to engage with the curriculum content, and reach certain learning objectives.

This use of SSI has often been described as "contexts for teaching curricular content," This conceptualization is based on the idea that SSI can engage students in the STEM learning process, since the SSI makes the content relevant to their life, or triggers an emotional response. As expressed in Romero-Ariza et al. [16]: "SSI are easily recognized by students as real-world scenarios related to contemporary issues, thus bringing a sense of authenticity and relevance to the science classroom" (p. 33). It is different, however, from previous approaches such as Science, Technology and Society (STS) because the way to appeal to students is through their moral implication [13].

Some of the papers reviewed in this investigation report experiences in which SSI is used as a pedagogical strategy, to help students reach specific learning goals, for example content knowledge and Socioscientific Reasoning (SSR) [35]; informal reasoning [4]; moral sensitivity [36]; Nature of Science (NoS) (for example Eastwood et al., [37]; Khishfe [38]; or what is referred as "Communication skills" [39].

The relevance of these papers to the objective of the present review are the relations that these establish with pedagogical strategies in STEM education. One of the most frequently mentioned is Inquiry-Based Learning scenarios (IBL) [22], [40]. As an adaptation of this strategy, Sadler et al. proposed the Socioscientific Issues Teaching and Learning 
model (SSI-TL) [41]. It constitutes a teaching and learning sequence that includes three main phases: 1) Encounter focal issue, where students are presented with the SSI; 2) Engage with explicit teaching and learning activities; and 3) Synthesize key ideas and practices.

Socio-Scientific Inquiry-Based Learning (SSIBL) is another adaptation of Inquiry-Based Learning to the context of SSI, combined with Citizenship Education (CE) [16]. The model addresses three principles. First, authenticity, understood as framing scientific content in a scenario that is relevant to students, and that it calls for action. Second, mapping controversy, which refers to understanding opposing sides of a fact from different perspectives, such as risk versus benefit, or ethical principles. Third, SSIBL teaches students to take action about the issue [42].

Other ways to conceptualize SSI in relation to STEM teaching and learning methodologies mention specific ways to engage students with the issue, namely dilemma and group discussion.

The dilemma (often referred to as the SSI itself) is a situation in which there is a need to decide between two alternatives, usually none of them being optimal. According to Ratcliffe, as applied to SSI, the dilemma focusses on the applications and implications of science [43]. Some characteristics of the dilemma are: 1) Attractive: Appeal to a reality that students can relate to; 2) Authentic: It deals with an issue that is connected to real life; 3) Controversial: Allows for different points of view [44]. An example of a dilemma could be: Should we ban plastic bags?. This has been referred to as the starting point of an SSI-based lesson [7].

In their proposal of "SSI cases," Ekborg et al. [7] also define the characteristics of pedagogically suitable dilemmas. They propose a framework for the design and analysis of SSI cases based on six components: 1) Starting point, 2) School science subject, 3) Nature of scientific evidence, 4) Social content, 5) Use of scientific knowledge, and 6) Level of conflict of interest.

Group discussion can be defined as an evidence-based conversation that takes place where several views are exposed about the same topic. When used as a pedagogical strategy, a debate asks students to make decisions and to understand the difference between opinions and evidence-based conclusions [45].

\section{CONCLUSION}

This paper responds to the need to undertake more systematic analysis of an educational practice that can be defined as SSI in formal education [10]. More specifically, the present study concerns the educational practice of SSI in formal STEM non-tertiary education.

As a result of a review of research about SSI in science education, and answering to the research question posed, this study elicited different conceptualizations of SSI in relation to the curriculum. These conceptualizations have been organized in four dimensions of the curriculum, namely: purpose, contents, teaching and learning methodologies, and assessment.

As per the first dimension, results show associations between SSI and two different ways to express the purpose of formal education: a) Citizenship education; and b) Scientific literacy or competence.

Looking at the STEM curriculum as a set of contents, both knowledge of science and knowledge about science have been clearly identified in the conceptualization of SSI. Additionally, its relation to skills such as argumentation has clearly emerged.

Considering the STEM curriculum in its dimension of teaching and learning methodologies, the following views have emerged: a) SSI is linked to pedagogical strategies such as inquiry-based learning; and c) SSI are related to pedagogical techniques such as dilemmas and group discussions.

These results have theoretical and practical implications. At a theoretical level, some of these results of this research are consistent with those obtained by Irez et al. [11] in their Delphi study. In particular there are commonalities in the applications of SSI to formal education that the authors refer to as "Learning outcomes" and "Pedagogical strategies," As for the first, the conceptualizations of SSI that appeared in this research under the curriculum component 2) Contents of formal science education, both knowledge of science and knowledge about science are represented. Skills such as argumentation are also in common, although our study could not provide evidence that all the references to argumentation as a skill are in fact "scientific argumentation skills," As for the second, i.e. "pedagogical strategies," our research confirms the prevalence of the association between SSI and Inquiry-Based Learning. On the contrary, it has not found evidence of other ways to operationalize it from a pedagogical strategies point of view such as cooperative learning or problem-based learning. Similarly, no evidence has been discovered supporting the association between SSI and pedagogical techniques such as brainstorming, storytelling or drama, whereas it confirms the presence of dilemmas and debates. or discussions

With respect to practice, a key value of this research is that, by eliciting the conceptualizations of SSI according to the curriculum, it could inform practitioners to better substantiate and promote the design of innovative SSI educational practices, according to different learning scenarios and learning strategies.

In terms of educational research, this study provides a sound link between the construct of SSI in educational practice, which is new, and specific dimensions of formal education as expressed in the curriculum, which is a more established construct in educational research. This link could inspire research that aims to establishing connections among practical applications of SSI in different subjects, cultural contexts, and educational systems. In turn, empirical studies could be compared or contrasted if the conceptualization of SSI in educational practice across them is compatible.

Our study shall also help to promote new lines of research. For example, the study was useful to certify that the conceptualization of SSI in formal education is diverse and formulated to different levels of detail and precision across the reviewed research. This is an area that could be investigated further and more systematically. Similarly, assessment is an important component of the curriculum, 
where conceptualizations of SSI are needed if it is to be implemented in formal education settings. The fact that no significant references have been found to SSI in relation to assessment criteria in this study is also an opportunity for further research.

\section{CONFLICT OF INTEREST}

The authors declare no conflict of interest.

\section{AUTHOR CONTRIBUTIONS}

Silvia Alcaraz-Dominguez co-designed, conducted the research, and wrote the paper; Mario Barajas guided the research and supervised it. Both authors approved the final version.

\section{REFERENCES}

[1] European Commission, Directorate-General for Research and Innovation, Europe 2020 Flagship Initiative - Innovative Union Communication from the Commission to the European Parliament, the Council, the European Economic and Social Committee and the Committee of the Regions, Luxembourg: Publications Office of the European Union, 2011.

[2] T. Jong, S. Sotiriou, and D. Gillet, "Innovations in STEM education: the Go-Lab federation of online labs," Smart Learning Environments vol. 1, no. 3, pp. 1-16, 2014.

[3] M. B. Ibáñez and C. Delgado-Kloos, "Augmented reality for STEM learning: A systematic review," Computers \& Education, vol. 123, pp. 109-123, 2018

[4] Y. T. Wu, "Reasoning on a Socio-scientific Issue Qualitative and quantitative analyses," International Journal of Science Education, vol. 29, no. 9, pp. 1464-5289, 2007.

[5] M. Barajas, A. Trifonova, and J. Giménez, "The Pathway to inquiry-based science education in Europe and beyond: challenges and solutions for IBSE adoption," Never Waste a Crisis! Inclusive Excellence, Innovative Technologies and Transformed Schools as Autonomous Learning Organisations, Athens, Greece: European Distance and E-Learning Network, 2011, pp.1-6.

[6] D. Zeidler, B. C. Herman, and T. D. Sadler, "New directions in socioscientific issues research," Disciplinary and Interdisciplinary Science Education Research, vol. 1, no. 11, pp. 1-9, 2019.

[7] M. Ekborg, M. Ideland, and C. Malmberg, "Science for life - A conceptual framework for construction and analysis of socio-scientific cases," Nordina, vol. 5, no. 1, 2009.

[8] M. Evagorou, J. A. Nielsen, and J. Dillon, Science Teacher Education for Responsible Citizenship towards a Pedagogy for Relevance through Socioscientific Issues, New York, NY: Springer, 2020.

[9] M. U. Genisa, B. Subali, B. Djukri, A. Agussalim, and H. Habibi, "Socio-scientific issues implementation as science learning material," International Journal of Evaluation and Research in Education, vol. 9, no. 2, pp. 311-317, 2020.

[10] N. Tekin, O. Aslan, and S. Yilmaz, "Research Trends on Socioscientific Issues: A Content Analysis of Publications in Selected Science Education Journals," Journal of Education and Training Studies, vol. 4, no. 9, pp. 16-24, 2016.

[11] S. Irez, A. Kilinc, C. Han-Tosunoglu, S. Caliskan, M. Demirbag, S. Yilmaz, A. Sonmez-Eryasar, M. Muzaffer Ozhan, S. N. Gungor, and Z. N. Koylu, "Towards developing a learning and teaching framework for SSI-based science education: results of a Delphi study," presented at the ESERA 2017 conference, Dublin, Ireland, August 21-25, 2017.

[12] D. Zeidler, "Socioscientific Issues as a Curriculum Emphasis: Theory, Research and practice," in Handbook of Research on Science Education, vol. 2, N. Lederman and S. Abell, Eds. New York, NY: Routledge, 2014, pp. 697-726.

[13] N. Lederman, A. Antink, and S. Bartos, "Nature of science, scientific inquiry, and socio-scientific issues arising from genetics: A pathway to developing a scientifically literate citizenry," Science and Education vol. 23, no. 2, pp. 285-302, 2014

[14] D. W. Stewart and M. A. Kamins, Applied Social Research Methods. Secondary Research, Thousand Oaks, CA: SAGE Publications, 1993.

[15] A. Harden and D. Gough, "Quality and relevance appraisal," in An Introduction to Systematic Reviews, D. Gough, D, S. Oliver, and J.
Thomas, Eds. London, United Kingdom: Sage Publications Ltd, 2012 pp. 153-179.

[16] M. Romero-Ariza, A. Abril, and A. Quesada, "Design and evaluation of teaching materials for responsible research and innovation," Sisyphus Journal of Education vol. 5, no. 3, pp. 28-43, 2017.

[17] A. C. Hadjichambis, Y. Georgiou, D. P. Hadjichambi, E. A. Kyza, A. Agesilaou, and D. Mappouras, "Promoting RRI and active citizenship in an inquiry-based controversial socio-scientific issue: The case of cholesterol regulation with statins," Journal of Biological Education, vol. 53 , no. $5,2018$.

[18] J. Stilgoe, R. Owen, and P. MacNaghten, "Developing a framework for responsible innovation," Research Policy, vol. 42, no. 9, pp. 1568-1580, 2013.

[19] W. L. Romine, T. Sadler, and A. T. Kinslow, "Assessment of scientific literacy: Development and validation of the Quantitative Assessment of Socio-Scientific Reasoning (QuASSR)," Journal of Research in Science Teaching, vol. 54, no. 2, pp. 274-295, 2017.

[20] A. B. Roig, A. V. Alonso, M. A. M. Mas, and A. García-Carmona, Ciencia, tecnología y sociedad en Iberoamérica: Una evaluación de la comprensión de la naturaleza de la ciencia y la tecnología, Madrid, Spain: Centro de Altos Estudios Universitarios de la OEI, 2010.

[21] A. Peel, L. Zangori, P. Friedrichsen, E. Hayes, and T. D. Sadler, "Students' model-based explanations about natural selection and antibiotic resistance through socio-scientific issues-based learning," International Journal of Science Education, vol. 41, no. 4, pp. 510-532, 2019.

[22] V. Albe, C. Barrué, L. Bencze, A. K. Byhiring, L. Carter, M. Grace, E. Knain, D. Kollst $\varnothing$, P. Reis, and E. Sperling, "Teachers' beliefs, classroom practices and professional development towards socioscientific Issues," in Topics and Trends in Current Science Education: 9th ESERA Conference Selected Contributions, Contributions from Science Education Research 1, C. Bruguière, A. Tiberghien, and P. Clément, Eds. Dordrecht, The Netherlands: Springer Science+Business Media, 2014, ch. 4, pp. 55-69.

[23] D. Zeidler and M. Newton, "Using a Socioscientific Issues framework for climate change education: An ecojustice approach," in Teaching and Learning about Climate Change: A Framework for Educators, D.P. Shepardson, A. Roychoudhury, and A. S. Hirsch, Eds. New York, NY: Routledge, 2017, ch. 5, pp. 56-66.

[24] N. Díaz-Moreno, E. C. Martín, and J. S. Nieto, "Using socioscientific issues as an educational tool to develop scientific literacy," International Journal of Educational Research and Innovation (IJERI), vol. 12, June, pp. 261-281, 2019.

[25] M. Ekborg, C. Ottander, E. Silfver, and S. Simon, "Teachers' experience of working with socio-scientific issues: A large scale and in depth study," Research in Science Education vol. 43, no. 2, pp. 599-617, 2013.

[26] M. Lundström, S. Sjöström, and H. Hasslöf, "Responsible research and innovation in science education: The solution or the emperor's new clothes?" Sisyphus Journal of Education, vol. 5, no. 3, pp. 11-27, 2017.

[27] A. Vázquez-Alonso and M. A. Manassero-Mas, "Contenidos de naturaleza de la ciencia y la tecnología en los nuevos currículos básicos de educación secundaria," Profesorado. Revista de curriculum y formación del profesorado vol. 21, no. 1, pp. 294-312, 2016.

[28] D. Zeidler, T. Sadler, M. L. Simmons, and E. V. Howes, "Beyond STS: A research- based framework for Socioscientific Issues education," Science Education vol. 89, no. 3, pp. 357-377, 2005.

[29] V. M. Dawson and G. Venville, "Teaching strategies for developing students' argumentation skills about socioscientific issues in high school genetics," Research in Science Education, vol. 40, no. 2, pp. 133-148, 2010.

[30] M. Evagorou, M. P. Jiménez-Aleixandre, and J. Osborne, "Should we kill the grey squirrels?" A study exploring students' justifications and decision-making," International Journal of Science Education, vol. 34 no. 3, pp. 401-428, 2012

[31] S. S. Lin and J. J. Mintzes, "Learning argumentation skills through instruction in socioscientific issues: The effect of ability level," International Journal of Science and Mathematics Education, vol. 8 , no. 6, pp. 993-1017, 2010.

[32] K. Rudsberg, J. Öhman, and L. Östman, "Analyzing students' learning in classroom discussions about socioscientific issues," Science Education, vol. 97, no. 4, pp. 594-620, 2013.

[33] N. A. Shea, R. G. Duncan, and C. Stephenson, "A tri-part model for genetics literacy: Exploring undergraduate student reasoning about authentic genetics dilemmas," Research in Science Education, vol. 45 , no. 4, pp. 485-507, 2014

[34] A. Garrido and D. Couso, "Socio-scientific issues (SSI) in initia training of primary school teachers: Pre-service teachers' 
conceptualization of SSI and appreciation of the value of teaching SSI," in Proc. 2014 International Conference on University Teaching and Innovation, CIDUI, 2014, pp. 80-88.

[35] S. Eggert, A. Nitsch, W. J. Boone, M. Nückles, and S. Bögeholz, 'Supporting students' learning and socioscientific reasoning about climate change - The effect of computer-based concept mapping scaffolds," Research in Science Education, vol. 47, no. 1, pp. 137-159, 2017

[36] S. Fowler, D. Zeidler, and T. D. Sadler, "Moral sensitivity in the context of socioscientific issues in high school science students," International Journal of Science Education, vol. 31, no. 2, pp. 279-296, 2009.

[37] J. Eastwood, T. D. Sadler, D. Zeidler, A. Lewis, L. Amiri, and S. Applebaum, "Contextualizing nature of science instruction in Socioscientific Issues," International Journal of Science Education, vol. 34, no. 15, pp. 2289-2315, 2012.

[38] R. Khishfe, "Explicit nature of science and argumentation instruction in the context of socioscientific issues: An effect on student learning and transfer," International Journal of Science Education, vol. 36, no. 6, pp. 974-1016, 2014.

[39] Y. Chung, J. Yoo, S. W. Kim, H. Lee, and D. Zeidler, "Enhancing students' communication skills in the science classroom through socioscientific issues," International Journal of Science and Mathematics Education, vol. 14, no. 1, pp. 1-27, 2016.

[40] M. Davut Gul and H. Akcay, "Structuring a new socioscientific issues (SSI) based instruction model: Impacts on pre-service science teachers (PSTs) critical thinking skills and dispositions," International Journal of Research in Education and Science (IJRES), vol. 6, no. 1, pp. 141-159, 2020

[41] T. D. Sadler, J. A. Foulk, and P. Friedrichsen, "Evolution of a model for socio-scientific issue teaching and learning," International Journal of Education in Mathematics, Science and Technology, vol. 5, no. 2, pp. 75-87, 2017.

[42] M. R. Ariza, A. M. Abril, A. Quesada, and F. J. Garcia, "Bridging inquiry based learning and science education on socio scientific issues: contributions to the PARRISE european project,"” in Proc. INTED2014: 8th International Technology, Education and Development Conf., 2014, pp. 2599- 2607.

[43] M. Ratcliffe, "Pupil decision-making about socio-scientific issues within the science curriculum," International Journal of Science Education, vol. 19, no. 2, pp. 167-182, 1997.

[44] A. Okada, G. Young, and T. Sherborne, "Innovative teaching of responsible research and innovation in science education," Elearning Papers, vol. 44, pp. 1-10, 2015.

[45] A. Okada, "Engaging Science: innovative teaching for responsible citizenship," Milton Keynes, United Kingdom: the Open University UK - knowledge media institute, 2016.

Copyright $\odot 2021$ by the authors. This is an open access article distributed under the Creative Commons Attribution License which permits unrestricted use, distribution, and reproduction in any medium, provided the original work is properly cited (CC BY 4.0).

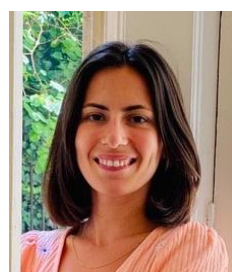

Silvia Alcaraz-Dominguez is from Barcelona (Spain). Alcaraz-Dominguez is a $\mathrm{PhD}$ candidate and an associate lecturer in Education at University of Barcelona (Spain). Ms. Alcaraz-Dominguez holds a Masters' Degree in Cognitive Systems and Interactive Media and a degree in Media, both from Pompeu Fabra University (Spain). Alcaraz-Dominguez's major field of study is science and technology in formal

education.

She has published part of her research in journals such as Journal of Research in Science Teaching (JRST). She developed and disseminated her research in Spain and other international institutions in Europe such as Technical University Delft (The Netherlands), Dublin City University (Ireland), Universidade de Lisboa (Portugal) and beyond, such as St. Peter's University (New Jersey, United States of America). She has presented and discussed her research in international conferences such as ESERA in Europe and NARST in the United States of America. Current research interests include formal education for citizenship, and the societal aspects of technology-enhanced learning especially in formal educational institutions. Ms. Alcaraz-Dominguez has earned the ESERA travel award and has served as a reviewer of international conferences such as NARST and of Digital Education Review, an indexed journal focusing on learning technologies.

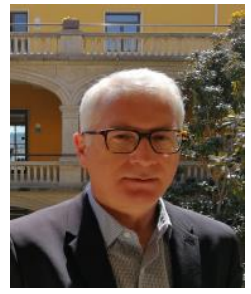

Mario Barajas is the head of the research group future learning (www.futurelearning.org), at the Faculty of Education of the University of Barcelona. $\mathrm{He}$ is a founder member of the Institute of Educational Research of the same University, he lectures in the area of digital education. During the last two decades, he has been undertaking research through different European Union funded projects in cloud education areas as STEM education, game-based learning, and

Dr. Barajas is member of different editorial boards and has published more than 100 academic articles, books, and Conference papers. 